\title{
Current Status of Fisheries and Aquaculture Statistics: A Brief Review
}

\author{
Constantine Stamatopoulos* \\ Fisheries Resources Monitoring and Assessment, Qatar
}

Submission: February 07, 2018; Published: April 26, 2018

Corresponding author: Constantine Stamatopoulos, International consultant, Fisheries Resources Monitoring and Assessment, Qatar, Email: cstamat@gmail.com

\begin{abstract}
The document briefly reviews the current status of statistical monitoring systems for fisheries and aquaculture. Emphasis is placed on small-scale fisheries and on small/medium water systems for freshwater aquaculture. Important sampling aspects such as determination of safe sample size and frequency of sampling are briefly presented and discussed. Also examined are survey operational aspects such as sustainability of data collection schemes and development/maintenance of databases used for the storage of primary data and the preparation of statistical reports.
\end{abstract}

Keywords: Statistical surveys; Sampling techniques; Small-scale fisheries; Freshwater aquaculture

\section{Introduction}

Reliable data on fisheries and aquaculture is a key factor for the formulation of policies and management. Knowledge of the status of capture fisheries is a prerequisite for sound policy-development, better decision-making and responsible fisheries management. Statistical monitoring of aquaculture production is important for assessing the contribution of fish in peoples' income and diet particularly in the case of several thousands of small units that are family-run.

A major task of most countries is the improvement of their data collection programmes relating to agricultural statistics, including fisheries and aquaculture. The advantage of sample-based fisheries statistical surveys is that they can make large-scale data collection programmes more affordable when sharp limitations exist with regards to human resources and availability of operational funds.

Of major importance is that the objective of a statistical monitoring programme be well understood by its users. In this respect the catch word is "monitoring" which means regularly conducted surveys for spotting important facts related to catch and effort such as overexploitation. And to cater of course for a large variety of statistical needs. This purpose is at times not fully understood and/or appreciated. For instance when during a closed season the system yields zero effort and zero production the result is disputed on the ground that there are offenders who should be spotted and reported. To do so the statistical monitoring system should have been conceived as a fisheries regulations enforcement instrument which it did not. In most cases illegal fishing is tacitly ignored if it concerns a few offenders. After all this is a job for the coast guards not for the statisticians.

A typical data collection scope for capture fisheries is catch, fishing effort, first-sale prices and average fish size. For inland aquaculture the scope is usually limited to the production of 4-5 primary species. The note briefly reviews the general features of national fisheries statistical programmes by highlighting achievements as well as occasional constraints and drawbacks. Although it is not a thorough analysis of exactly what is being done and where it can nevertheless provide a reasonably accurate picture as to how this application sector is handled by fisheries administrations in developing countries.

\section{Target Populations in Capture Fisheries and Freshwater Aquaculture}

There are usually two target populations in capture fisheries and one in freshwater aquaculture. In capture fisheries we examine the population of landings that are made by a specific fleet segment over a reference period (almost invariably a month). In most cases this population has a known size and conforms to the characteristics of a continuous variable. Mostly it is skewed with higher density around one or two points. The total landings divided by the total trip days yield an important compound average known as the CPUE (=catch-per-unit-effort). This average is estimated by means of sampling. 
The second population has the same size as the first and it is binary (or dichotomous). Its elements are the values 0 and 1 appearing at variable proportions and expressing the status of a boat on a given day, i.e. $1=$ fishing and $0=$ no fishing. The mean proportion expresses the probability that any boat of a fleet segment is active on any day. This probability is estimated by means of sampling and it is subsequently used to estimate total fishing effort and then total production in combination with the CPUE.

While there is practically only one data collection scenario for landings, for fishing effort there are two different approaches for estimating the PBA (=probability boat active). The first approach examines randomly pre-selected boats and records the number of those that went out fishing. In the second approach the effort survey is integrated into the landings survey whereby fishermen provide answers on the days worked over a week or during the month. Each of the two approaches has its merits and drawbacks and also different sampling requirements. The second approach tends to be more robust statistically but its reliability depends on the willingness of the fishermen to cooperate.

In the case of freshwater aquaculture the target population is usually composed of small ponds managed by families and of larger water systems such as barrages and small lakes where concessionaries and/or recreational fishers go to fish. The two are treated as different segments in a manner similar to fleet segments in capture fisheries. Here fishing effort is not measured in the same fashion as before; ponds can be active or inactive (for maintenance) but sample harvest is usually collected at the end of a month without differentiating between active and inactive ponds. The number of ponds along with the days in the month is used to formulate a CPUE-type indicator by dividing sample harvest by the total number of ponds in the sample multiplied by the days in the month.

\section{Common Misconceptions}

One of the very first rules in statistical surveys is making sure that the target population is the right one. This might seem selfevident but the author's experience in the matter urges him to point out that the rule is not always observed. The most frequent misconception is that the population to be sampled is the fleet or the fishermen and that their number determines the population size. Such a misconception might lead to wrong decisions concerning frequency and size of sampling. Admittedly the answer is not obvious: in a landings survey the population is the landings made during the month, in boat activities the population is a large matrix with $0-1$ elements expressing boat status over a period, in monthly effort the population is, just this time, the fishermen.

The second frequent misconception is to think of sampling in terms of percentages of population elements to sample. This is in fact more inexact than wrong in that a certain sampling percentage might be insufficient for a small population and superfluous for a larger one. The right approach is to determine sample size and frequency on the basis of the size of the sub-populations (i.e. strata) generated by each fleet segment and by also considering the type of data collection scenario in use. Such decisions would need some extent of calculations but there exist simple computer utilities to cater for that.

During the design of a statistical monitoring programme certain decisions have to be made concerning the sampling scenarios to be used and the operational aspects of data collection. Most often the fleet is partitioned into segments of boats-gears that operate similarly; geographical stratification is incorporated to facilitate distributing the work and better respond to local needs. This is commonly known as stratification process. A frequent misconception is that the purpose of stratification is to reduce variance. Instead stratification is used to reduce the risk of bias and the reduced variance comes too but only as a bonus. This question is at times used at statistical exams by professors who are in the habit of setting traps for their students. Another aspect which is at times overlooked is that each new stratum increases data collection costs because it has its own sampling needs. For new strata to share the same samples determined earlier is a rather serious misconception that can compromise the reliability of the final results.

\section{Training}

Systematic training in fisheries statistics with emphasis on sampling helps avoiding the misconceptions discussed earlier. Training usually involves two audiences:

(i) Field staff and,

(ii) Statisticians and researchers.

Typical training of field staff comprises a practical understanding of the populations to be sampled, the use of data collection forms (whether electronic or hardcopy), species and boat-gear identification and application of data collection protocols. The latter concern detailed data collection instructions for each fleet segment indicating the frequency of sampling and the required sample size. Supplementary workshops on database operations are a typical follow-up to statistical training. Training of the second audience focuses on basic statistical analysis such as standardization of fishing effort and catch-per-unit-effort (CPUE), exportation of database results for further analysis, elements of descriptive statistics and basic statistical analysis.

\section{Database Systems}

An essential component of a statistical monitoring system for fisheries and aquaculture is the implementation of a database for the effective storage, processing and analysis of the collected data. Development is usually left to the skills of specialized companies or to individuals who are well conversant with modern techniques of systems design. When this development is done collectively and with frequent advice from the statisticians providing the methodology things generally work out well and the system responds satisfactorily to users' needs. There are instances however that the IT expert has obtained little feedback from the statistics experts with the result that the system is in the end short 
of some essential functions, such as automatic estimation of catch/ effort, analytical reports, etc. In such cases users have to extract the data themselves and analyze them externally; a rather poor usage of a (usually) costly product.

\section{Conclusion}

In the end one may conclude that despite problems, misconceptions and sporadic failures today's national statistical monitoring systems are in a much better shape than they used to be 15-20 years ago. This is partly due to the pressure by international and regional fisheries bodies for data of finer definition and higher timeliness and accuracy. Several technical assistance projects at national and regional level played a significant role in promoting effective data collection schemes and development and use of databases. Most importantly it was the national fisheries administrations themselves that have realized the importance of regularly operated statistical monitoring programmes for fisheries and aquaculture and have invested considerably in equipment and human resources despite chronic budgetary constraints. It is true that there is still much room for improvement but the prospects are positive and most importantly there is an increasing number of national experts who are quite capable of developing and supporting statistical programmes of the type discussed in the note. This new development should solve for good the most serious and chronic problem in national fisheries statistical programmes: sustainability.

\section{Your next submission with Juniper Publishers} will reach you the below assets

- Quality Editorial service

- Swift Peer Review

- Reprints availability

- E-prints Service

- Manuscript Podcast for convenient understanding

- Global attainment for your research

- Manuscript accessibility in different formats ( Pdf, E-pub, Full Text, Audio)

- Unceasing customer service

Track the below URL for one-step submission https://juniperpublishers.com/online-submission.php 